\begin{tabular}{|c|l|}
\hline Title & The Zoraptera problem : evidence for Zoraptera + Embiodea from the wing base \\
\hline Author(s) & Yoshizawa, Kazunori \\
\hline Citation & $\begin{array}{l}\text { Systematic Entomology, 32(2), 197-204 } \\
\text { https:/doi.org/10.1111j.1365-3113.2007.00379.x }\end{array}$ \\
\hline Issue Date & 2007-04 \\
\hline Doc URL & http://hdl.handle.net/2115/33766 \\
\hline Rights & The definitive version is available at www.blackwell-synergy.com \\
\hline Type & article (author version) \\
\hline File Information & SE32-2.pdf \\
\hline
\end{tabular}

Instructions for use 
To be published in Systematic Entomology

\title{
The Zoraptera problem: evidence for Zoraptera + Embiodea from the wing base
}

\author{
KAZUNORI YOSHIZAWA
}

Systematic Entomology, Graduate School of Agriculture, Hokkaido University, Sapporo, Japan

Running title: Zoraptera problem

Correspondence: Kazunori Yoshizawa, Systematic Entomology, Graduate School of Agriculture, Hokkaido University, Sapporo 060-8589, Japan; E-mail: psocid@res.agr.hokudai.ac.jp Tel: +81-11-706-2424

Fax: +81-11-706-4939

\begin{abstract}
The order Zoraptera is one of the most enigmatic insect groups. Its phylogenetic position is far from being settled, and more than 10 different placements have been discussed since the insects were first discovered. This problem is also difficult to resolve molecularly because of unusual characteristics of zorapteran $18 \mathrm{~S}$ rDNA sequences which is the most widely used genetic marker to estimate the deep phylogeny of insects. In this study, the wing base structure of Zoraptera and various potential sister taxa was examined. Numbers of unique modifications were detected in the wing base structure of Zoraptera, and six of them were also observed in the wing base of Embiodea (webspinners). No possible synapomorphies supporting the other relationships were detected. These are the second unambigous morphological synapomorphies providing strong evidence for the phylogenetic position of Zoraptera.
\end{abstract}

\section{Introduction}

Phylogenetic placement of the Zoraptera is one of the most controversial problems among the higher systematics of insects, and the order has the most variation in phylogenetic placement across separate phylogenetic hypotheses (Kristensen, 1991; Rasnitsyn, 1998; Engel \& Grimaldi, 2000, 2002; Grimaldi \& Engel, 2005). Since their first discovery (Silvestri, 1913), more than 10 different systematic placements have been discussed (Engel \& Grimaldi, 2002). Currently the order is considered to belong to the hemimetabolous Neoptera. Although this placement is widely accepted, exact position of Zoraptera is far from being settled and is still actively debated (Beutel \& Weide, 2005). Beutel \& Weide (2005) expressed this confusion as the "Zoraptera problem", comparing it to the "Strepsiptera problem", the only other insect order that has such confusing relationships (Kristensen, 1991; Whiting et al., 1997). Despite their low specific diversity, Zoraptera also show unusual aspects of biology and behaviour (Valentine, 1986; Choe, 1997). Therefore, their systematic placement attracts attentions not only from systematic entomologists but also from evolutionary biologists. 
Some earlier and even recent hypotheses (e.g., being primitive thrips or holometabolan sister) were based only on superficial similarities and/or misinterpretations of morphological characters and thus are now generally rejected (Engel \& Grimaldi, 2000, 2002; Beutel \& Weide, 2005). To date, the following four hypothetical sister groups of Zoraptera are still plausible morphologically: Dermaptera (Jarvis et al., 2005; Terry \& Whiting, 2005), Dictyoptera (Boudreaux, 1979; Wheeler et al., 2001), Embiodea (or Embioptera: Minet \& Bourgoin, 1986; Engel \& Grimaldi, 2000, 2002; Grimaldi \& Engel, 2005) and Paraneoptera (Hennig, 1953; Beutel \& Weide, 2005). Each hypothesis is supported by more than one morphological apomorphy, but most of which are more or less homoplastic.

A clear conclusion regarding the Zoraptera problem was not obtained either by molecular or combined morphology + molecular phylogenetic analyses. Yoshizawa \& Johnson (2005) analysed $18 \mathrm{~S}$ rDNA sequences of a wide range of insects aligned according to secondary structure, and the resultant tree supported the Zoraptera + Dictyoptera hypothesis. However, unusual characteristics observed in the zorapteran 18S sequences are highly problematic for phylogenetic estimation (Kjer, 2004; Yoshizawa \& Johnson, 2005) which can also be compared to the still controversial problem of the molecular placement of Strepsiptera (Carmean \& Crespi, 1995; Huelsenbeck, 1998; Maddison, 2004). Terry \& Whiting (2005) analysed combined morphology + molecular data selected from a wide range of the lower Neoptera, and resultant trees supported Zoraptera + Dermaptera. They also gave a taxon name, Haplocercata, for this clade. However, their analytical methods and morphological coding involve some problems (discussed below). Therefore, results from molecular and combined phylogenetic analyses must also be tested by independent data sets.

The wing base structure in insects can be a potential source of deep phylogenetic information. The rate of evolution of the wing base structure is kept low probably due to functional restrictions of the complex flying and wing folding mechanisms (Hörnschemeyer, 2002). Because of this, the wing base structure has been used as an important source of information for the supra-ordinal phylogeny of insects (Yoshizawa \& Saigusa, 2001; Hörnschemeyer, 2002). The wing base structure in Paraneoptera (Yoshizawa \& Saigusa, 2001) and Holometabola (Hörnschemeyer, 2002) was investigated in detail recently, but the wing base structure in Polyneoptera is very poorly understood. In the present study, I examined the morphology of the wing base structure in Zoraptera and various putative sister groups to clarify the systematic placement of the order.

\section{Materials and methods}

Morphological observations were based on both dried and wet (preserved in $99.5 \%$ or $80 \%$ ethanol) specimens. The thorax was separated and placed in $10 \% \mathrm{KOH}$ solution at room temperature overnight. The material was then rinsed with distilled water and stored in $80 \%$ ethanol for subsequent dissection. To facilitate observation, the sternum, pleuron, and ventral layer of wings were removed. Observation and illustration was made in glycerol using a Leica MZ 12 stereoscopic microscope and Zeiss Axiophoto compound light microscope.

The taxa examined are listed in the Appendix. Although I examined the wing base structure of all winged orders of hemimetabolous Neoptera and a few representatives of Holometabola, illustrations are only shown for Plecoptera, Dermaptera, Dictyoptera (Isoptera), Phasmatodea, Embiodea, Paraneoptera (Psocodea), and Zoraptera. Plecoptera were selected because they are 
considered to have the wing base which is close to the neopteran ground plan (Matsuda, 1970; Yoshizawa \& Saigusa, 2001; Hörnschemeyer, 2002). Dermaptera, Dictyoptera, Embiodea, and Paraneoptera were selected as possible candidates for the zorapteran sister group. Phasmatodea were selected because recent molecular analyses (Terry \& Whiting, 2005) and the present examination suggested closer relationships between Phasmatodea and Embiodea/Zoraptera. More detailed descriptions of the wing base structure and its transformation in hemimetabolous Neoptera has been and will be discussed elsewhere (Yoshizawa \& Saigusa, 2001; Yoshizawa, 2005, in prep). In deciding polarity of character states, examination of the palaeopteran outgroup is required. However, homologization of wing base structures between Neoptera and palaeopterans is extremely difficult and is beyond the scope of the present study. Here, polarity of characters were decided only when homology could be identified confidently using one exemplar of Ephemeroptera. Terminologies of structures followed Yoshizawa \& Saigusa (2001) (but the terms head and neck of the first axillary sclerite were adopted instead of the anterior arm of 1 Ax according to Hörnschemeyer, 2002) and higher taxon names followed Grimaldi \& Engel (2005).

In the following discussion, I focus only on the hindwing base structure for the following reasons. In insects with less specialized wings (e.g., Plecoptera, Zoraptera), modifications of the fore- and hindwing bases appear almost parallel to each other. Therefore, in such cases, examination of one of two wings was informative enough. In contrast, insects with highly specialized wings (e.g., Dermaptera) show autapomorphic modifications in the forewing base structure, and such modifications are less valuable for supra-ordinal phylogenetic estimation. Furthermore, such extreme modifications might erode useful phylogenetic information and thus can provide homoplastic noise.

The determination of the homology of the axillae was initiated by identifying the first axillary sclerite, which is recognizable by articulations with the anterior and median notal wing processes. Using the first axillary sclerite as a landmark, homologies of other sclerites were detected based on their relative positions, articulations, fold and flexion lines, and relationships with wing veins (see also Wootton, 1979; Yoshizawa \& Saigusa, 2001). The ligament of the second axillary sclerite and posterior notal wing process were also used for additional landmarks, if necessary. Fold and flexion lines were observed by manipulating the wings of $\mathrm{KOH}$ soaked but non-dissected specimens.

\section{Results}

Generalized wing base characters that are relevant to the systematic placement of Zoraptera can be described as follows (Fig. 1; see Yoshizawa \& Saigusa, 2001 and Hörnschemeyer, 2002 for detailed description of the general wing base morphology in Neoptera): (1:0) hindwing tegula (Tg) very weakly developed or even absent; (2:0) posterior notal wing process (PNWP) fused with notum, and basal hinge runs between distal end of PNWP and third axillary sclerite (3Ax); (3:0) head of first axillary sclerite (1Ax) not enlarged; (4:0) posteroproximal corner of 1Ax free from PNWP; (5:0) basiradiale (BR) not divided, but the convex axillary fold line runs through the proximal part of $\mathrm{BR}$ and the region is composed of flexible cuticle; (6:0) ligament toward ventral 2Ax occurs at the middle of 2Ax; (7:0) humeral plate (HP) well developed; (8:0) neck of 1 Ax not broadened. Judging from the wing base structure in Ephemeroptera, these generalized features were considered to represent plesiomorphies, except for the ligament of $2 \mathrm{Ax}(6: 0)$ because no ligament was observed in the ephemeropteran $2 \mathrm{Ax}$ and thus polarity of this character could not be decided. 
In comparison to the above mentioned generalized features, the wing base structure in Zoraptera shows highly specialized features as follows (Fig. 2A): (1:1) hindwing Tg enlarged; (2:1) PNWP detached from notum, and basal hinge runs between proximal margin of the detached PNWP and notum; (3:1) head of 1Ax enlarged; (4:1) posteroproximal part of 1Ax fused with anteroproximal part of the detached PNWP; $(5: 1)$ proximal part of BR separated into two sclerites along the convex axillary fold line; $(6: 1)$ the ligament toward the ventral $2 \mathrm{Ax}$ occurs at the posterior end of $2 \mathrm{Ax} ;(7: 1)$ HP absent or indistinguishably fused with costa; (8:1) neck of 1Ax broadened.

In Embiodea (Fig. 2B), apomorphic states (including a tentative one) of characters 1-6 were observed which were considered to indicate their close relationship. Detachment of PNWP from the notum (2:1) and enlargement of the head of 1Ax (3:1) were also observed in Phasmatodea (Fig. 2C). Terry \& Whiting (2005) supported the monophyly of Phasmatodea + Embiodea (termed Eukinolabia). The presence of these apomorphies in Phasmatodea does not contradict with a Zoraptera + Embiodea clade, but could even provide support for a close relationship between Phasmatodea and Embiodea + Zoraptera. Apomorphic conditions of characters 7 and 8 were neither observed in Embiodea nor in other orders and thus were considered to be autapomorphies of Zoraptera.

Homologies of some highly modified characters (characters 2 and 5) for which alternative interpretations could be possible were identified as follows:

- Character 2: In most winged insects, PNWP arises from the posterolateral region of the notum (2:0 in Fig. 1), and 3Ax articulates proximally with PNWP along the basal hinge and concave axillary fold line (these two lines are united and cannot be distinguished posteriorly: Fig. 1). In contrast, 3Ax of Zoraptera and Embiodea articulates proximally with a sclerite detached from the notum (Fig. 2AB). This feature is clearly different from the plesiomorphic condition and thus can be regarded as their synapomorphy, but homology of the detached sclerite is arguable. The concave axillary fold line runs between the detached sclerite and 3Ax (Fig. 2AB) and, using the fold line as a landmark, the sclerite could be homologized with PNWP (2:1). Alternatively, the basal hinge runs between the detached sclerite and notum (Fig. 2AB) and, using the basal hinge as a landmark, the sclerite could be homologized with a part of $3 \mathrm{Ax}$. These two alternative interpretations both require two steps of morphological transformations (i.e., detachment of PNWP and movement of the basal hinge vs. separation of proximal part of $3 \mathrm{Ax}$ and movement of the convex axillary fold line) and thus are equally plausible. However, the former interpretation seems to be more reasonable because in Zoraptera and Embiodea, the lateral margin of the notum is nearly straight and no projection corresponding to PNWP is extended. In addition, 3Ax of Phasmatodea (Fig. 2C) also articulates proximally with a sclerite detached from the notum, and both the basal hinge and concave axillary fold line run between the detached sclerite and 3Ax. Using the basal hinge and concave axillary fold line as landmarks, the detached sclerite in Phasmatodea can be clearly homologized with PNWP (Fig. 2C). This character state seems to represent an intermediate condition between (2:0) and (2:1) and, as mentioned above, Phasmatodea appear to be close to the Zoraptera + Embiodea clade (Terry \& Whiting, 2005). Therefore, detachment of PNWP from the notum and movement of the basal hinge $(2: 1)$ is considered here to be the most reasonable interpretation (Fig. 2). This interpretation is also in agreement with Matsuda (1970: figs 50, 53a).

- Character 5: In many Neoptera, BR and 2Ax are fused with each other and their boundary is less distinct (Fig. 1B-D). However, in Plecoptera, BR and 2Ax are clearly separated by a narrow 
membranous region (Fig. 1A). The convex axillary fold line runs through BR and the region is composed of flexible cuticle (Fig. 1A, 5:0), and BR can be separated into the proximal and distal regions by the concave axillary fold line (Fig. 1). In Embiodea, a unique sclerite surrounded by $1 \mathrm{Ax}$, $2 \mathrm{Ax}$ and base of the radial vein was observed (indicated by an asterisk in Fig. 2B), and the convex axillary fold line runs through the membranous region between the sclerite and base of the radial vein. Using the convex axillary fold line as a landmark, the sclerite can be clearly homologized with the proximal region of BR (5:1). Similarly, in Zoraptera, the convex axillary fold line runs through the membranous region at the proximal end of radial vein. This condition is in complete agreement with that of Embiodea and thus is considered here to be their synapomorphy (5:1). In Phasmatodea, BR is partly fused with the head of $1 \mathrm{Ax}$ (Fig. 2C). It represents a highly autapomorphic condition, and homologization of the proximal part of BR is difficult. The convex axillary fold line apparently runs through a narrow flexible sclerite and thus 5:0 was adopted for Phasmatodea (Fig. 2C), but the sclerite indicated by an asterisk (Fig. 2A-C) seemed to be homologous throughout these three orders.

No further possible synapomorphy, which suggested closer relationship between Zoraptera and other insect orders were detected (Figs 1-2). Enlargement of Tg (1:1) was observed in the forewings of Fulgoromorpha (Hemiptera) and Thysanoptera (Yoshizawa \& Saigusa, 2001), but not in the hindwings. Fusion of $1 \mathrm{Ax}$ and PNWP (4:1) can be regarded as a consequence of elongation of the posteroproximal corner of $1 \mathrm{Ax}$, and the latter condition can also be observed in many different orders (e.g., Plecoptera, Mantodea, Phasmatodea). However, even when the posteroproximal corner of $1 \mathrm{Ax}$ has an extreme extension (e.g., Plecoptera), fusion of 1Ax and PNWP was never observed. Differentiation of the fourth axillary sclerite (4Ax), which is homologous with the distal part of PNWP, was reported for some holometabolous insects (e.g., Neuroptera, Mecoptera: Hörnschemeyer, 2002). However, my present examination confirmed that the basal hinge in these insects runs between the distal end of $4 \mathrm{Ax}$ and the proximal tip of $3 \mathrm{Ax}$, retaining the plesiomorphic condition (2:0). Furthermore, 4Ax of Neuroptera and Mecoptera was firmly connected to the notum or basal part of PNWP, and a membranous flexible region was not detected between them (2:0). Therefore, differentiation of $4 \mathrm{Ax}$ observed in these holometabolous insects is not homologous with the similar condition observed in Zoraptera and Embiodea.

\section{Discussion}

A total of six putative synapomorphies of Zoraptera and Embiodea were identified. The fusion of 1Ax and PNWP (4:1) is especially important because this modification involves changing the mode of wing flapping and folding mechanisms that is considered to be established by two sequential modifications. First, the separation of PNWP from the notum, as observed in Phasmatodea (Fig. $2 \mathrm{C}$ ), should have occurred which eventually provided movement of the basal hinge from the distal end of PNWP (2:0 in Figs 1, 2C) to the proximal margin of the detached PNWP (2:1 in Fig. 2AB). Without this modification, fusion of 1Ax and PNWP would make it impossible to flap and fold wings because the basal hinge runs between 1Ax and PNWP in the plesiomorphic condition (Fig. 1). Thus, the fusion of 1Ax and PNWP (4:1) should have occurred after detachment of PNWP from the notum (2:1). The basal hinge is the principal wing hinge in flight (Wootton, 1979) and thus retains a fundamental condition throughout the winged insects. Zoraptera and Embiodea are the only exceptions showing modification of the basal hinge. 
The wings of Isoptera are similar to those of Zoraptera and Embiodea in many aspects (i.e., presence of basal fraction zone, paddle-like shape, reduction of veins, and presence of apterous form). Isoptera are also similar to Zoraptera and Embiodea in having the gregarious life style and inhabiting narrow galleries. Nevertheless, the specialized wing base structures observed in Zoraptera and Embiodea were not seen in the isopteran wing base (Fig. 1C) which retains rather plesiomorphic condition as observed in the Blattodea. Therefore, it is less conceivable that the modifications of the wing base observed in Zoraptera and Embiodea have evolved independently in correlation with the specialization of wing morphology and behavior. In addition, no homoplasy which contradicts with Zoraptera + Embiodea is detected. Therefore, as far as wing base structure is concerned, monophyly of Zoraptera + Embiodea is very strongly supported.

Until now, more than 10 alternative hypotheses on the systematic placement of Zoraptera have been proposed (see Introduction). Some hypotheses are now generally rejected, but still the following four taxa are considered to be potential sister groups by morphological and/or molecular phylogenetic analyses: Paraneoptera, Dictyoptera, Dermaptera and Embiodea.

Zoraptera + Paraneoptera was first proposed by Hennig (1953) and subsequently relatively widely accepted (e.g., Kristensen, 1975). Their potential synapomorphies are smaller numbers of malpighian tubes (6/4: Zoraptera/Paraneoptera), tarsomeres (2/3 or less) and abdominal ganglia (2/1). Recently, Beutel \& Weide (2005) added the strong development of the delator muscle of the cibarium as a potential synapomorphy, but the muscle is much less developed in Zoraptera compared to Paraneoptera (Yoshizawa \& Saigusa, 2003; Beutel \& Weide, 2005; Yoshizawa, pers. obs.) perhaps calling this homology into question. In addition, reduction of the tarsomere (also observed in Embiodea, etc.), reduction of malpighian tubes (highly variable among or even within orders), reduction of abdominal ganglia (sometimes highly variable even within an order), and strong development of the cibarial muscle (also observed in Blattodea) are highly homoplastic which do not strongly support Zoraptera + Paraneoptera. Three additional potential synapomorphies suggested by Beutel \& Weide (2005) are questionable: (1) presence of the anteclypeus - the anteclypeus is not differentiated in some psocopterans (suborder Trogiomorpha) (Yoshizawa \& Saigusa, 2003); (2) median rim of prementum - such rim is not developed in some psocopterans (suborder Troctomorpha) (Yoshizawa, 2005). These suborders are considered to preserve the primitive features of Psocoptera (Yoshizawa et al., 2006) and Psocoptera preserve the primitive features of Paraneoptera (Yoshizawa \& Saigusa, 2001). Thus these character states may not represent the ground plan of Paraneoptera but evolved independently in some paraneopteran clades. Furthermore, the latter condition may even represent a plesiomorphy of Neoptera because it is also observed in different groups of Polyneoptera. (3) Narrowed lacinia without mesally directed spines or setae - the lacinia in Zoraptera shows similar condition with that of psocopterans but differs in lacking the basal detachment from the stipes and ingrowth of sclerite developed from the lateral margin (Yoshizawa \& Saigusa, 2003; Beutel \& Weide, 2005; Yoshizawa, pers. obs.). Both psocopterans and Zoraptera probably use the lacinia to loosen the food substrate in a similar manner (Badonnel, 1934; Beutel \& Weide, 2005). Therefore, functional convergence of the lacinia could also be assumed.

Zoraptera + Dictyoptera was first proposed by Boudreaux (1979). Combined morphological and molecular analysis by Wheeler et al. (2001) also supported this hypothesis, and the following four morphological characters were considered to be their synapomorphies: discoid pronotum, forward slanting pleural suture, reduction of indirect wing muscles, and modified coxa. Of them, 
reduction of the indirect wing muscles is inapplicable because these muscles are well developed in winged forms and also distinctly present in apterous forms of Zoraptera (Beutel \& Weide, 2005). Other possible synapomorphies are highly homoplastic or may actually represent plesiomorphic conditions (Beutel \& Weide, 2005). Neither separate molecular or morphological analyses by Wheeler et al. (2001) supported close relationship between Zoraptera and Dictyoptera. Therefore, more recent authors recognized this hypothesis as less plausible (Beutel \& Weide, 2005). The Zoraptera + Dictyoptera hypothesis recently received relatively strong support from independent molecular analysis of 18S (99\% Bayesian posterior probability and 54\% likelihood bootstrap support: Yoshizawa \& Johnson, 2005), but the gene shows very unusual evolutionary characteristics, such as modifications of secondary structure, long insertions, and dramatically accelerated substitution rate. As mentioned by Kjer (2004) and Yoshizawa \& Johnson (2005), such unique properties are highly problematic for phylogenetic estimations and thus the $18 \mathrm{~S}$ phylogeny is also not decisive.

Zoraptera + Dermaptera was first proposed by Carpenter \& Wheeler (1999) based on direct optimization of morphology and molecular (18S and 28S) data. Recently, the relationship received further support from the combined morphology and molecular (18S, 28S and Histone 3 genes) data analysed by direct optimization and Clustal + Bayesian analyses (Terry \& Whiting, 2005). However, their results involve some problems. First, their analytical methods (i.e., direct optimization and Clustal alignment) might be problematic. As mentioned by Kjer (2004), conclusion by direct optimization can be highly dependent on some combination of noise from the homoplastic data and arbitrarily optimized homology of unalignable data. Clustal alignment is also problematic when sequences contain long insertions/deletions (Yoshizawa \& Johnson, 2003). The partition Bremer support values from direct optimization indicated that the $18 \mathrm{~S}$ data also involves significant signal for Zoraptera + Dermaptera (Terry \& Whiting, 2005), but Yoshizawa \& Johnson (2005) clearly showed that the conserved regions of $18 \mathrm{~S}$ have little signal supporting it. Therefore, signals for Zoraptera + Dermaptera detected by Terry \& Whiting (2005) probably come from highly homoplastic and/or poorly aligned regions that are less reliable for deep phylogeny. Second, possible morphological synapomorphies of Zoraptera + Dermaptera (Jarvis et al., 2005; Terry \& Whiting, 2005) are mostly based on misinterpretations as follow: single segmented cerci - cerci of some fossil zorapteran (Zorotypus goeleti) and Dermaptera (Archidermaptera and Eodermaptera) have more than one segment (Carpenter, 1992; Engel \& Grimaldi, 2000; Grimaldi \& Engel, 2005) and thus single segmented cerci is not a ground plan character of both orders; absence of ocelli - not applicable for winged forms of Zoraptera (Beutel \& Weide, 2005; Yoshizawa, pers. obs.); thigmotactic behaviour highly homoplastic.

Zoraptera + Embiodea was first proposed by Minet \& Bourgoin (1986) and later accepted as the best hypothesis by Engel \& Grimaldi $(2000,2002)$ based on an expanded list of synapomorphies. Their potential synapomorphies are the enlargement of metafemora with unique musculature, reduced number of tarsomeres, paddle-shaped wings with basal fraction zone, presence of apterous morphs, one or two segmented cerci, loss of gonostyli, vestigial ovipositor, and gregarious lifestyle (Engel \& Grimaldi, 2000, 2002; Grimaldi \& Engel, 2005). One additional potential synapomorpy, the differentiation of the anteclypeus, was detected by Beutel \& Weide (2005). However, as mentioned by Beutel \& Weide (2005), nearly all of these potential synapomorphies are loss characters and/or highly homoplastic, as in the case for the other 
hypotheses discussed above (except the reversed musculature of the metafemora). Nevertheless, the Zoraptera + Embiodea hypothesis is supported by the largest number of potential synapomorphies. The present study adds a considerable number of unambiguous synapomorphies which strengthen the Zoraptera + Embiodea hypothesis (Mirorder Mystroptera: Rafael \& Engel, 2006).

\section{Acknowledgements}

I thank A.B. Idris, Y. Kamimura, H. Kojima, S. Koshikawa, S. Nomura, I. Ohshima, A. Otsuki, $\mathrm{H}$. Suenaga and N. Takahashi for providing specimens (including identified ones), especially F-T. Krell and D. Goodger for lending specimens of a critical taxon, Clothodidae, from the Natural History Museum, London. I also thank B. J. Sinclair for critical comments and correcting the English, and R. G. Beutel, M. S. Engel, and C. Szumik, referees of the paper, for their kind and constructive comments. Some samples were collected during a Tropical Asia insects inventory project conducted by O. Yata supported by the JSPS grant 142550161, and this paper was partly supported by the JSPS grant 18770058 to KY.

\section{References}

Badonnel, A. (1934) Recherches sur l'anatomie des Psoques. Bulletin Biologique de France et de Belgique, Supplement 18, 1-241.

Beutel, R.G. \& Weide, D. (2005) Cephalic anatomy of Zorotypus hubbardi (Hexapoda: Zoraptera): new evidence for a relationship with Acercaria. Zoomorphology, 124, 121-136

Boudreaux, H.B. (1979) Arthropod Phylogeny, with Special Reference to Insects. Wiley, New York.

Carpenter, F.M. (1992) Treatise on Invertebrate Paleontology, Part R, Arthropoda 4, Volume 3: Superclass Hexapoda. The Geological Society of America, Kansas.

Carpenter, J.M. \& Wheeler, W.C. (1999) Cladistica numérica, análisis simultáneo y filogenia de hexápodos. Boletin de la Sociedad Entomológica Aragonesa, 26, 333-346.

Carmean, D. \& Crespi, B.J. (1995) Do long branches attract flies? Nature, 373, 666.

Choe, J.C. (1997) The evolution of mating systems in the Zoraptera: mating variations and sexual conflicts. The Evolution of Mating Systems in Insects and Arachnids, pp. 130-145. Cambridge University Press, Cambridge.

Engel, M.S. \& Grimaldi, D. (2000) A winged Zorotypus in Miocene amber from the Dominican Republic (Zoraptera: Zorotypidae), with discussion on relationships of and within the order. Acta Geológica Hispanica, 35, 149-164.

Engel, M.S. \& Grimaldi, D. (2002) The first Mesozoic Zoraptera (Insecta). American Museum Novitates, 3362, 1-20.

Grimaldi, D. \& Engel, M.S. (2005) Evolution of the Insects. Cambridge University Press, Cambridge.

Hennig, W. (1953) Kritische Bemerkungen zum phylogenetischen System der Insekten. Beiträge zur Entomologie, 3, 1-85.

Hörnschemeyer, T. (2002) Phylogenetic significance of the wing-base of the Holometabola (Insecta). Zoologica Scripta, 31, 17-29.

Huelsenbeck, J.P. (1998) Systematic bias in phylogenetic analysis: is the Strepsiptera problem solved? Systematic Biology, 47, 519-537. 
Jarvis, K.J., Haas, F. \& Whiting, M.F. (2005) Phylogeny of earwigs (Insecta: Dermaptera) based on molecular and morphological evidence: reconsidering the classification of Dermaptera. Systematic Entomology, 30, 442-453.

Kjer, K. (2004) Aligned 18S and insect phylogeny. Systematic Biology, 53, 506-514.

Kristensen, N.P. (1975) The phylogeny of hexapod orders. A critical review of recent accounts. Zeitschrift für zoologische Systematik und Evolutionsforschung, 13, 1-44.

Kristensen, N.P. (1991) Phylogeny of extant hexapods. The Insects of Australia, $2^{\text {nd }}$ ed., Vol. 1, pp. 125-140. Melbourne University Press, Victoria.

Maddison, D.R. (2004) Are strepsipterans related to flies? Exploring long branch attraction. Mesquite: a modular system for evolutionary analysis, version 1.04. Available via http:// mesquiteproject.org.

Matsuda, R. (1970) Morphology and evolution of the insect thorax. Memoirs of the Entomological Society of Canada, 76, 1-431.

Minet, J. \& Bourgoin, T. (1986) Phylogenie et classification des Hexapodes (Arthropoda). Cahiers Liaison, O.P.I.E., 20, 23-28.

Rafael, J. A. \& Engel, M. S. (2006) A new species of Zorotypus from Central Amazonia, Brazil (Zoraptera: Zorotypidae). American Museum Novitates, 3528, 1-11.

Rasnitsyn, A.P. (1998) On the taxonomic position of the insect order Zorotypida = Zoraptera. Zoologischer Anzeiger, 237, 185-192.

Silvestri, F. (1913) Descrizione di un nuovo ordine di insetti. Bollettino del Laboratorio di Zoologia Generale e Agraria, Portici, 7, 193-209.

Terry, M.D. \& Whiting, M.F. (2005) Mantophasmatodea and phylogeny of the lower neopterous insects. Cladistics, 21, 240-257.

Valentine, B.D. (1986) Grooming behavior in Embioptera and Zoraptera (Insecta). Ohio Journal of Science, 86, 150-152.

Wheeler, W.C., Whiting, M., Wheeler, Q.D. \& Carpenter, J. M. (2001) The phylogeny of the extant hexapod orders. Cladistics, 17, 113-169.

Whiting, M.F., Carpenter, J.C., Wheeler, Q.D. \& Wheeler, W.C. (1997) The Strepsiptera problem: phylogeny of the holometabolous insect orders inferred from $18 \mathrm{~S}$ and $28 \mathrm{~S}$ ribosomal DNA sequences and morphology. Systematic Biology, 46, 1-68.

Wootton, R.J. (1979) Function, homology and terminology in insect wings. Systematic Entomology, 4, 81-93.

Yoshizawa, K. (2005) Morphology of Psocomorpha (Psocodea: 'Psocoptera'). Insecta Matsumurana, New Series, 62, 1-44.

Yoshizawa, K. \& Johnson, K.P. (2003) Phylogenetic position of Phthiraptera (Insecta: Paraneoptera) and elevated rate of evolution in mitochondrial 12S and 16S rDNA. Molecular Phylogenetics and Evolution, 29, 102-114.

Yoshizawa, K. \& Johnson, K.P. (2005) Aligned 18S for Zoraptera (Insecta): phylogenetic position and molecular evolution. Molecular Phylogenetics and Evolution, 37, 572-580.

Yoshizawa, K., Lienhard, C. \& Johnson, K.P. (2006) Molecular systematics of the suborder Trogiomorpha (Insecta: Psocodea: 'Psocoptera'). Zoological Journal of the Linnean Society, 146, 287-299.

Yoshizawa, K. \& Saigusa, T. (2001) Phylogenetic analysis of paraneopteran orders (Insecta: 
Neoptera) based on forewing base structure, with comments on monophyly of Auchenorrhyncha (Hemiptera). Systematic Entomology, 26, 1-13.

Yoshizawa, K. \& Saigusa, T. (2003) Reinterpretations of clypeus and maxilla in Psocoptera, and their significance in phylogeny of Paraneoptera (Insecta: Neoptera). Acta Zoologica (Stockholm), 84, 33-40. 


\section{Figure captions}

Fig. 1. Hindwing base structure, dorsal view. Abbreviations: 1, 2, 3Ax = first, second, and third axillary sclerites; ANWP, MNWP, PNWP = anterior, median, and posterior notal wing processes; $\mathrm{BR}=$ basiradiale; $\mathrm{BSc}=$ basisubcostale; $\mathrm{DMP}, \mathrm{PMP}=$ distal and proximal median plates; HP = humeral plate; $\mathrm{Tg}=$ tegula. Italicized numbers indicate character state (see text). A. Nemoura sp. (Plecoptera); B. Labidula riparia (Dermaptera); C. Reticulitermes speratus (Isoptera); D. Longivalvus nubilus (Psocodea).

Fig. 2. Hindwing base structure, dorsal view. Abbreviations as indicated for Fig. 1. Asterisks indicate the detached BR. A. Zorotypus sp. VN. (Zoraptera), posterolateral corner of the tegula and apices of the bristles on tegula covering important morphological characters are omitted; B. Oligotoma sp. (Embiodea); C. Sipyloidea sipylus (Phasmatodea). 
Appendix. Taxa examined.

'PALAEOPTERA'

Ephemeroptera: Siphlonuridae - Genus unidentified

\section{POLYNEOPTERA}

Plecoptera: Nemouridae - Nemoura; Perlidae - Kamimuria, Oyamia; Chloroperlidae - Alloperla Dermaptera: Spongiphoridae - Labia; Labiduridae - Labidura; Forficulidae - Timomenus.

Mantodea: Acromantidae - Acromantis; Hymenopodidae - Creobroter; Mantidae - Mantis, Satilia, Tenodera

Blattodea: Derocalymmidae - Trichoblatta; Pycnoscelidae - Pycnoscelis; Blattidae - Periplaneta; Epilampridae - Rhabdoblatta

Isoptera: Rhinotermitidae - Coptotermes, Reticulitermes; Termopsidae - Hodotermopsis; Termitidae - Nasutitermes, Pericapritermes

Embiodea: Clothodidae - Antipaluria; Oligotomidae - Oligotoma (2 spp.)

Zoraptera: Zorotypidae - Zorotypus (2 spp.)

Phasmatodea: Phasmatidae - Micadina, Sipyloidea; Phylliidae - Phyllium; Pseudophasmatidae Pseudophasma (from Matsuda, 1970)

Orthoptera: Tettigoniidae - Tettigonia; Acrididae - Eirenephilus; Tetrigidae - Criotettix

\section{PARANEOPTERA}

See Yoshizawa \& Saigusa (2001)

\section{HOLOMETABOLA}

Megaloptera: Corydalidae - Protohermes, Parachauliodes, Neochauliodes; Sialidae - Sialis

Neuroptera: Hemerobiidae - Micromus; Ascalaphidae - Syphalomitus

Mecoptera: Bittacidae - Bittacus; Panorpidae - Panorpa 

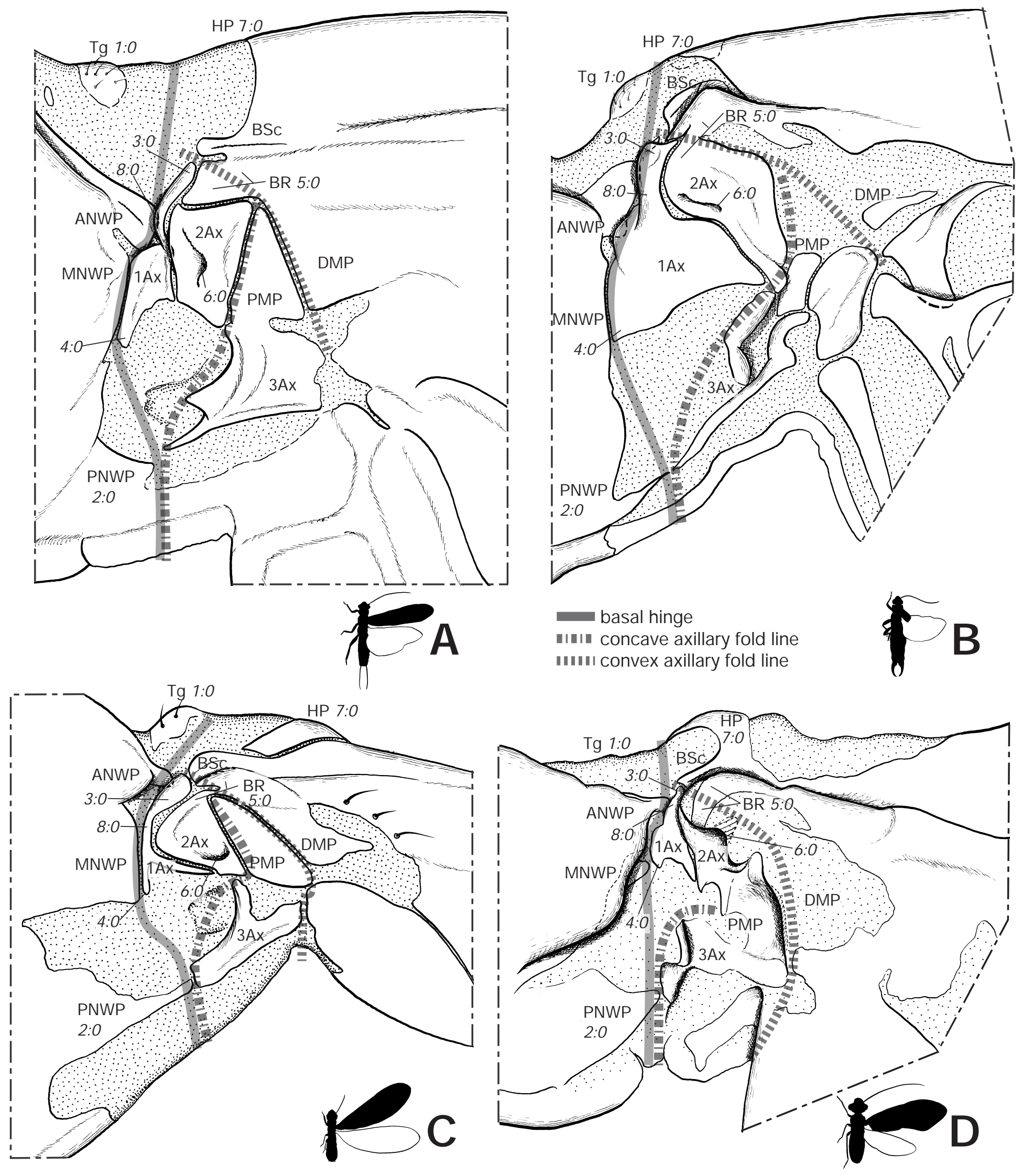

Fig. 1 


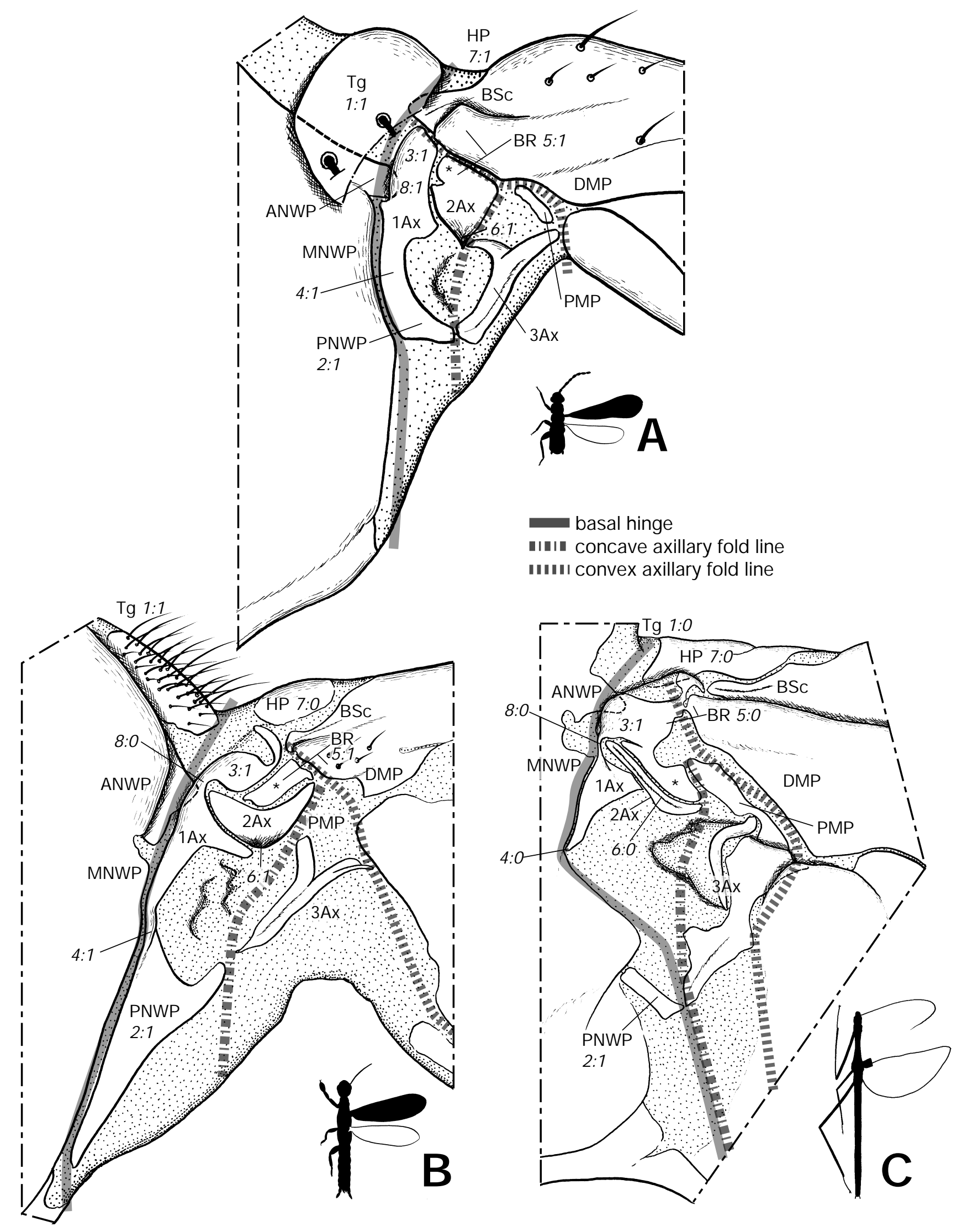

Fig.2 